\title{
Educação permanente de docentes: análise crítica de experiências não sistematizadas
}

\section{Continuing education of medical teachers: critical analysis of non- systematic experiences}

\author{
Henriqueta Galvanin Guidio de Almeida ${ }^{1}$ \\ Olavo Franco Ferreira Filho ${ }^{1}$
}

\author{
PALAVRAS-CHAVE: \\ - Educação Continuada. \\ - Educação Médica. \\ - Aprendizagem Baseada em \\ Problemas.
}

Recebido em: 29/06/2007

Reencaminhado em: 02/02/2008 Aprovado em: 10/02/2008

\begin{abstract}
R E S U M O
Quando alterações curriculares abrangentes são propostas para os cursos de Medicina, como no caso da implantação de um currículo integrado, exige-se do professor a modificação de seu papel central de transmissor de conhecimentos para um papel mais cooperativo e facilitador do processo de ensino-aprendizagem, o que pode gerar insegurança, sensação de perda de poder e resistência. A capacitação formal dos docentes para suas novas funções é imperiosa para o sucesso nas mudanças. Além das ações educativas sistematizadas, atividades alternativas podem contribuir para aperfeiçoar a função docente. Este artigo analisa a experiência de docentes do curso de Medicina da Universidade Estadual de Londrina (UEL), membros das comissões de apoio ao colegiado, que desenvolveram, nos primeiros anos da implantação do currículo integrado, atividades não sistematizadas de educação permanente junto a docentes do curso. São comentadas informações a respeito: da reunião semanal realizada com os tutores; da pesquisação sobre a inserção e o desenvolvimento docente no currículo integrado; da revisão dos conteúdos dos módulos temáticos; da pesquisação com os coordenadores dos módulos temáticos; e do inquérito realizado com os preceptores de áreas do internato médico. As atividades analisadas forneceram respostas a demandas locais e contribuíram com a dinâmica de um processo de implantação que deve permanecer em contínua renovação.
\end{abstract}

\section{A B S T R A C T}

Whenever great changes in the curriculum of medical courses are proposed, as is the case in the current implementation of an integrated curriculum, the teachers are expected to change their role from mere knowledge providers to a more cooperative and integrating role, facilitating the teaching-learning process. Such changes can cause insecurity, a sense of powerlessness and consequently resistance to these changes. To qualify the teachers for their new functions is thus pivotal for the success of any curricular changes. Besides the systematic educational actions, alternative activities can also contribute to the improvement of the teaching practice. This article analyzes the experience of teachers from the Londrina State University Medical School (UEL), who participated in the group responsible for developing non-systematic education activities with the teaching body of the medical course during the first year of the implementation of the integrated curriculum. The following activities are commented: the weekly meetings with tutors, the action-research on the development and insertion of the teaching body in the integrated curriculum, the topic-based module content reviews, the action-research with the topic-based module coordinators and the survey carried out with the coordinators of internship areas. The analyzed activities provided answers for local needs and contributed to a dynamic and continuously renewed implementation process.
REVISTA BRASILEIRA DE EDUCAÇÃO MÉDICA $240 \frac{242): 240-247: 2008}{32(2)}$

\footnotetext{
${ }^{1}$ Universidade Estadual de Londrina, Paraná Brasil.
} 


\section{INTRODUÇÃO}

A inadequação da formação do egresso das escolas médicas para o desempenho de seu papel na sociedade, tanto no campo profissional como nos campos político e social, vem sendo reconhecida mundialmente. No Brasil, na década de 1990, a Comissão Interinstitucional de Avaliação do Ensino Médico (Cinaem) detectou deficiências no processo de formação do médico em relação tanto ao egresso como ao corpo docente e ao modelo pedagógico adotado pelos cursos ${ }^{1}$. Alternativas vêm sendo adotadas nacionalmente na tentativa de reverter esse quadro.

A publicação das Diretrizes Curriculares Nacionais do Curso de Graduação de Medicina impulsionou mudanças nas escolas médicas ao estabelecer, entre outras orientações, o perfil do egresso como um médico de formação geral, humanista, crítica e reflexiva, pautado em princípios éticos, atuando com promoção, prevenção, recuperação e reabilitação da saúde, com responsabilidade social e compromisso com a cidadania ${ }^{2}$.

Posteriormente, ocorreram outras iniciativas destinadas a impulsionar, apoiar e consolidar as mudanças no ensino médico, tais como: o Programa de Incentivo a Mudanças Curriculares nos cursos de Medicina (Promed) ${ }^{3}$ e o Programa Nacional de Reorientação da Formação Profissional em Saúde (Pro-Saúde) ${ }^{4}$. Também contribuindo para as mudanças do ensino médico, surgiram as iniciativas de adoção de metodologias ativas no processo de ensino-aprendizagem.

As novas escolas de ensino superior que iniciam suas atividades com a implantação de metodologias inovadoras têm, a princípio, um desafio importante a vencer: a capacitação docente para as diversas funções demandadas pelo currículo.

Nas escolas com currículos tradicionais e que se propõem a mudanças curriculares significativas, o desafio de capacitar professores é acrescido de outro, não menos importante, que é o enfrentamento da resistência de docentes às inovações e ao exercício das novas atividades.

Quando alterações curriculares abrangentes são propostas para os cursos de Medicina, devem se considerar outros fatores para que se aumente a chance de consolidar as mudanças. No curso de Medicina da UEL, a maioria dos professores médicos não tem formação didático-pedagógica adequada, baseando sua prática educacional em modelos profissionais encontrados durante sua formação ${ }^{5}$. Tendem a considerar as tarefas de ensino menos importantes do que sua prática médico-assistencial ou mesmo do que suas atividades de pesquisa.

Os novos currículos exigem a modificação do papel central de transmissor de conhecimentos para um papel mais cooperativo, facilitador do processo de ensino-aprendizagem e integrador com outras disciplinas tanto nas atividades de planejamento como na execução das tarefas, trazendo ao médico docente sensações de insegurança e de perda de poder e gerando resistência. O aperfeiçoamento das funções docentes não costuma encontrar oportunidade adequada entre as múltiplas tarefas a que esses profissionais se propõem, sendo sempre alegada falta de tempo para realizá-lo.

Recente $\operatorname{artigo}^{6}$ descreve com pertinência os possíveis fatores que dificultam as mudanças da prática docente em medicina. São lembrados a desvalorização da prática docente em contraposição à supervalorização da pesquisa, a falta de identidade da profissão docente, a incipiente capacitação pedagógica dos professores, a resistência deles frente às mudanças e o individualismo da ação docente.

Assim, a introdução de mudanças educacionais sistematizadas numa escola médica deve ser acompanhada de reflexões sobre estratégias de como enfrentar os grandes desafios que o corpo docente produzirá.

A capacitação docente formal é imperiosa para currículos inovadores ${ }^{7,8}$. O planejamento e a execução de atividades educativas devem ser preocupação nuclear para o grupo de professores que pretenda implantar novas metodologias de ensino-aprendizagem.

Além das ações educativas sistematizadas, atividades alternativas podem contribuir para o aperfeiçoamento da função docente. Ao lado dos objetivos centrais propostos para estas atividades, agregam-se objetivos que favorecem também a capacitação dos professores. São procedimentos auxiliares informais, não sistemáticos, que podem contribuir para a formação docente durante um processo de mudança.

A implantação do currículo integrado no curso de Medicina da UEL ocorreu há dez anos. As atividades da Comissão de Treinamento (CT) - que durante o processo de implantação foi renomeada para Comissão de Capacitação Docente (CCD) e hoje se denomina Comissão de Educação Permanente Docente (CEPD) - foram intensas nos primeiros anos, e as iniciativas formais dessa Comissão com dados quantitativos e qualitativos foram analisadas em artigo publicado em $2003^{9}$. Além dessas ações, um grupo de professores ligados às comissões de apoio do colegiado do curso, ao participar de múltiplas atividades não planejadas formalmente com finalidades didático-pedagógicas, conseguiu vivenciar o que se denominou de experiências não sistematizadas de educação permanente.

Este artigo analisa cinco dessas experiências. A primeira delas se refere a um processo muito rico de capacitação coletiva dos docentes que atuaram intensamente nos dois primeiros anos da 
implantação do novo currículo. As outras se referem a momentos em que a capacitação ocorreu como objetivo paralelo, embora não menos importante e intencional.

\section{REUNIÃO DE TUTORES}

Os primeiros alunos do currículo integrado do curso iniciaram suas atividades em 1998. Naquele ano, as outras cinco séries da graduação permaneceram com o currículo anterior.

No novo currículo, a metodologia da Aprendizagem Baseada em Problemas (ABP) foi adotada para os módulos temáticos das quatro primeiras séries do curso. O ponto alto da semana padrão de cada série passou a ser as sessões tutoriais, que acontecem duas vezes na semana, sendo os 80 alunos divididos em dez grupos, cada um sob a orientação de um professor-tutor. Cada sessão tutorial dura, em média, duas horas.

Apesar do intenso treinamento, em 1997, dos professores que iriam atuar como tutores junto aos alunos da primeira série, as profundas mudanças em seu papel transmitiam a necessidade de estabelecer momentos que permitissem uma compreensão mais aprofundada das novas funções.

Embora não tenham sido constituídas com a finalidade de capacitar professores, mas, sim, de gerenciar os problemas surgidos durante a implementação dos módulos temáticos, as reuniões de tutores desempenharam também esse papel.

Planejadas para acontecer num período do dia em que não ocorriam atividades com os alunos (período liberado para estudo individual), as reuniões eram semanais e duravam em torno de duas horas. Delas participavam o coordenador do módulo em andamento e os dez tutores, além de representantes das diversas Comissões que auxiliavam o colegiado na implantação do currículo, denominadas comissões de apoio (Avaliação, Treinamento, Acompanhamento).

Durante a reunião, os tutores expunham individualmente as dificuldades de desempenho ocorridas durante as sessões tutoriais realizadas na semana. Eram referidos problemas relacionados a: dinâmica de grupo, aplicação dos passos da sessão tutorial, procedimento frente a alunos muito calados ou excessivamente participativos, avaliação formativa dos alunos, como oferecer e estimular a consultoria junto a outros docentes da escola, problemas mal elaborados ou com distratores, e objetivos de aprendizagem propostos para o módulo não atingidos por alguns problemas.

Era um desafio administrar o clima de ansiedade e insegurança de professores e alunos frente às novas experiências de ensino-aprendizagem. A convivência dos calouros com os vetera- nos possibilitava a comparação de atividades dos dois currículos e favorecia a insegurança e resistência dos alunos iniciantes.

Com a ajuda do coordenador do módulo e dos representantes das comissões, as dificuldades eram discutidas e em seguida sugeridas soluções. Nas questões gerenciais e de conteúdo modular, o coordenador do módulo exercia função decisiva; nas outras questões, a opinião dos representantes de comissões tinha um papel fundamental no embasamento teórico das sugestões propostas. Problemas ligados à infra-estrutura física, comuns nessa fase do processo, eram levados às reuniões da Comissão de Acompanhamento da Implantação do Currículo, vinculada à direção administrativa da universidade, para as tentativas de solução.

A discussão e o equacionamento de problemas reais encontrados no início da implantação do método da ABP proporcionaram um clima propício ao processo de ensino-aprendizagem dos professores. A freqüência e a duração dos encontros favoreceram o processo de capacitação. O desejo de conduzir de forma adequada e bem-sucedida a construção do processo local contribuiu de forma decisiva para o caráter formativo das reuniões. Esse talvez tenha sido um dos momentos mais férteis da capacitação coletiva dos docentes em ABP no curso de Medicina de Londrina.

Com a implementação do currículo integrado na segunda série, foi mantida uma reunião de tutores para cada série. No terceiro ano, porém, com o envolvimento de maior número de docentes na função de tutor, as reuniões semanais foram se esvaziando, e era alegado excesso de atividade dos professores (ambulatórios, enfermarias, cirurgias, outras atividades didáticas e de pesquisa), o que os impedia de comparecer a mais uma reunião semanal além das duas já dedicadas às sessões tutoriais. Assim, como solução, optou-se por marcar uma reunião mais curta (30 minutos) logo no início de uma das sessões tutoriais, comparecendo os tutores e o coordenador do módulo, sem os representantes das comissões de apoio. Com tempo exíguo de duração, as reuniões lamentavelmente perderam, desde então, suas características especiais de educação permanente, mantendo somente características gerenciais referentes às atividades do módulo.

\section{PESQUISAÇÃO SOBRE A INSERÇÃO E O DESENVOLVIMENTO DOCENTE NO CURRÍCULO INTEGRADO}

Com o currículo integrado sendo progressivamente implantado nas quatro primeiras séries do curso, crescia, paralelamente ao número de alunos, a demanda de professores para atender as várias atividades a serem desenvolvidas. 
Particularmente, a elaboração dos módulos temáticos a serem implementados pela primeira vez exigia grande esforço das comissões de apoio ao colegiado no treinamento de professores das diversas disciplinas para as tarefas de inserção de seus conteúdos nos módulos interdisciplinares (construção dos módulos, inserção de conferências e aulas práticas), para a elaboração de problemas e as tarefas de tutoria.

A participação dos docentes nas várias atividades passou a ser indispensável e não voluntária, como havia sido até então, quando somente os mais interessados e entusiasmados desempenhavam múltiplas funções.

Em 2001, quando foi implantada a quarta série do novo currículo, a demanda de recursos humanos para manutenção do funcionamento do curso de graduação era bastante elevada.

Para discutir a visão dos professores vinculados ao curso de Medicina acerca do processo de implantação do novo currículo, sensibilizar e incentivar a inclusão docente nos trabalhos, a Comissão de Capacitação Docente (CCD), apoiada pelo colegiado e pela direção do Centro de Ciências da Saúde da UEL, realizou uma atividade de pesquisa sobre inserção e desenvolvimento docente.

A pesquisa consistiu na aplicação de um questionário estruturado com 43 questões fechadas a todos os professores que atuavam no curso de Medicina. Dos 268 professores, 220 responderam o questionário.

Os resultados desse inquérito foram publicados em dois artigos: Ferreira Filho et al. (2002) $)^{10}$ e Almeida et al. (2003) $)^{11}$.

Essa pesquisa teve um papel fundamental no sentido de conhecer os professores no que se refere à sua capacitação pedagógica, identificar seus anseios de aprimoramento docente, avaliar sua opinião acerca da metodologia de ensino adotada no curso e conhecer sua inserção atual no novo currículo.

Para obter respostas de um número representativo de docentes, os membros da CCD realizaram um intenso trabalho de mobilização, utilizando o contato pessoal por meio de entrevistas, contatos por correio eletrônico, contatos telefônicos, visitas, contatos indiretos via amigos e por vias administrativas (estruturas departamentais). O estreitamento das relações dos entrevistadores com os professores permitiu que um grupo significativo de docentes utilizasse essa oportunidade para esclarecer dúvidas a respeito do método e manifestasse de forma mais aberta suas percepções e críticas quanto ao novo currículo e à forma de implementação do processo, além de formular sugestões que julgavam pertinentes.

A busca ativa das respostas às perguntas contidas no questionário contribuiu para um verdadeiro processo informal de capa- citação, porque permitiu a todos os docentes, na medida de seu interesse e solicitação, receber de forma individualizada informações nucleares e fundamentais acerca da nova organização curricular e da metodologia de ensino adotada. Essas ações favoreceram sobremaneira a diminuição das resistências, tornando mais democrática e inclusiva a implantação do processo, embora também tenha se verificado uma parcela de respondentes que encaravam a pesquisa de forma burocrática e responderam formalmente aos questionamentos.

Dados de literatura sustentam que, quando líderes de curso não dão a devida atenção às preocupações dos docentes quanto às demandas de uma inovação educacional, os professores podem atuar de forma não cooperativa, cometendo, às vezes, graves desvios em sua atuação ${ }^{12}$. Neste sentido, a pesquisação com os docentes teve um caráter cooperativo positivo.

\section{REVISÃO DOS CONTEÚDOS DOS MÓDULOS TEMÁTICOS}

Em 2002, com a chegada dos alunos do currículo integrado ao internato médico, vários professores das áreas profissionalizantes do curso expressaram, de forma direta ou velada, sua preocupação quanto às possíveis falhas no desempenho desses alunos em suas novas funções e o quanto esse fato poderia estar relacionado às profundas mudanças ocorridas na metodologia de ensino-aprendizagem e de organização curricular.

Considerando esse fato, entre outras atitudes, o colegiado constituiu, estrategicamente, a Comissão de Revisão Curricular (CRC), cujo objetivo principal era verificar e assegurar que os tópicos de um currículo nuclear mínimo necessário à formação do médico geral fossem abordados durante os seis anos do curso.

O primeiro trabalho da CRC foi desenvolvido por meio da análise dos conteúdos dos módulos temáticos das quatro séries iniciais do curso com a colaboração dos coordenadores. Todos os tópicos abordados nas diversas atividades dos módulos foram levantados. A seguir, esses tópicos foram agrupados por áreas correspondentes às antigas disciplinas dos ciclos básico e pré-clínico. Os coordenadores dessas áreas foram convocados a opinar quanto à suficiência ou não dos respectivos tópicos.

Em outra fase do trabalho, os membros da CRC discutiram as manifestações dos coordenadores das antigas disciplinas, sempre tendo em vista a formação do médico geral. Recomendaram, então, inserções de tópicos considerados nucleares e não contemplados na elaboração dos módulos e supressão de conteúdos redundantes, apontando onde essas alterações deveriam ser realizadas. 
Os coordenadores dos módulos foram, então, reconvocados para receber as sugestões da CRC e discutir sua implementação junto com os membros dos grupos que realizavam o replanejamento anual dos módulos. Com esse trabalho, foi cumprida também importante tarefa de capacitação docente em muitos aspectos, em particular esclarecendo e justificando a interdisciplinaridade da organização modular. Dados de literatura registram a preocupação com a pouca integração do conteúdo temático e com a ausência de interdisciplinaridade quando os módulos são coordenados por especialistas ${ }^{7}$. No presente relato, grande parcela dos coordenadores era especialista.

A verificação da inserção dos tópicos presentes no currículo deu aos professores a visibilidade das respectivas áreas, valorizando-as e contribuindo para diminuir resistências.

Alguns autores são de opinião de que a excessiva preocupação dos professores em cobrir todo o conteúdo de sua disciplina pode gerar atitudes inadequadas em relação ao auto-aprendizado dos alunos ${ }^{12}$. Na fase de implantação de uma inovação curricular, porém, a reflexão sobre esses conteúdos pode ser atrativa e motivar a cooperação dos docentes com o processo.

Vale a pena citar os objetivos positivos alcançados com essa atividade e registrados pelos membros da CRC em seu relatório final ${ }^{1}$ :

a) A discussão do currículo propiciou aumento do interesse de muitos docentes em participar de forma mais ativa no modelo atual.

b) Tornou-se acessível ao corpo docente o entendimento da maneira pela qual as disciplinas se integram no currículo.

c) A inserção de novos tópicos no currículo certamente aprimorou sua qualidade.

d) Houve melhor esclarecimento a respeito das tarefas que os docentes podem exercer no novo modelo curricular.

e) Houve aumento da compreensão, por parte dos coordenadores de módulo, da importância de sua função e da necessidade de maior troca de informações entre eles.

f) Foi identificada a necessidade de melhor capacitação para todas as funções docentes, particularmente para a coordenação de módulo, e participação nos grupos de planejamento dos módulos temáticos.

g) O trabalho da Comissão resultou em importante passo para o aprimoramento do currículo, embora persistam nele limitações e defeitos a corrigir oportunamente.

h) Evidenciou-se a necessidade de complementação de conteúdo curricular durante o internato médico.
Infelizmente, esta iniciativa permanece única, não tendo sido reproduzida nos anos seguintes. Pode ser vista como um desafio para a coordenação do curso.

\section{PESQUISAÇÃO COM OS COORDENADORES DOS MÓDULOS TEMÁTICOS}

Motivada pela necessidade de padronizar e melhorar o desempenho dos coordenadores dos módulos temáticos, a Comissão de Capacitação Docente realizou, em 2003, uma atividade que envolvia pesquisa e capacitação.

Foi construído um formulário semi-estruturado com 25 questões que foram aplicadas pelos membros da CCD aos coordenadores dos módulos em momento previamente agendado e acordado. As questões versavam sobre as principais tarefas a serem cumpridas pelos coordenadores de módulo quanto ao planejamento, organização e desenvolvimento dos módulos. Foram incluídas questões sobre dificuldades mais freqüentes vivenciadas por eles no exercício da função e conhecimento das possíveis instâncias de apoio. Por último, foram questionados a respeito da realização de discussões com os grupos de replanejamento dos módulos sobre as sugestões da CRC de modificação (inserção ou retirada) dos tópicos modulares e a efetivação dessas mudanças. Todos os coordenadores dos 24 módulos participaram das entrevistas, que duraram em média 40 minutos.

Obtidas as respostas, o entrevistador discutia com o coordenador questões que eram respondidas inadequadamente.

Constatou-se a existência de lacunas no conhecimento de algumas disposições operacionais, mas a maioria mostrou domínio teórico das questões abordadas ${ }^{14}$. A atividade teve o mérito de permitir o treinamento individualizado dos coordenadores, diversificando o número de itens discutidos e sua profundidade de acordo com a demanda de cada um.

Novamente, o lamentável é não ter se dado continuidade à iniciativa.

\section{INQUÉRITO REALIZADO COM OS PRECEPTORES DE ÁREAS DO INTERNATO MÉDICO}

Em 2004, dando seqüência ao trabalho iniciado em 2002 nos módulos temáticos, a Comissão de Acompanhamento Curricular (antiga CRC) planejou o levantamento dos tópicos abordados com os alunos da quinta e sexta séries nos diversos estágios do internato médico. O objetivo da Comissão foi identificar e adequar o currículo nuclear do vigente curso para formar o médico geral.

Foi encaminhado aos preceptores de todos os estágios do internato um questionário que solicitava as seguintes informa- 
ções: programa teórico do estágio e sua forma de desenvolvimento; programa prático do estágio com sua quantificação e especificação dos locais onde é desenvolvido; identificação de competências a serem atingidas pelos alunos naquele estágio, visando à formação do médico geral; planilhas de competências para o estágio. Essas planilhas descreviam que o médico geral, ao final de seu estágio, deveria ser capaz de: diagnosticar e tratar; reconhecer e adotar conduta de emergência; suspeitar e encaminhar; saber fazer.

A consolidação das respostas ofereceu uma visão geral da programação do internato médico naquele momento. Segundo as informações dos preceptores, "fica evidente que o número de horas e a variedade de atividades teóricas, práticas e teórico-práticas oferecidas aos alunos oportuniza a eles a aquisição de conhecimentos, habilidades e atitudes suficientes para exercer as funções esperadas para o médico geral pretendido por esta escola médica"15.

Os resultados do inquérito foram amplamente divulgados e disponibilizados a todos os interessados. Particularmente, constituiu um subsídio importante para os debates que a Preceptoria Geral do internato programou para o VII Seminário do Internato, realizado no final daquele ano.

Além de cumprir seu objetivo específico, relativo ao currículo nuclear, essa atividade da CAC permitiu o cumprimento de objetivos paralelos: mobilizou grande número de docentes das áreas profissionalizantes para pensar sobre o internato; ressaltou aos docentes de cada estágio a importância de planejar, executar e avaliar suas atividades para atingir os objetivos propostos; instigou a discussão sobre o grau de coerência entre o atual internato médico da UEL e o currículo integrado; colaborou para que um número maior de médicos refletisse sobre seu papel enquanto docentes de uma escola médica.

\section{DISCUSSÃO E CONSIDERAÇÕES FINAIS}

O curso de Medicina da UEL iniciou suas atividades há 40 anos e desde então tem procurado manter dinâmico seu desenvolvimento científico e tecnológico na área médica, assim como seu desenvolvimento na área educacional ${ }^{16}$.

Em 1991, durante a Fase I do Projeto Cinaem (Comissão Interinstitucional de Avaliação das Escolas Médicas), foram identificadas fragilidades no modelo pedagógico adotado no curso médico da UEL e deficiente capacitação de muitos professores.

Até 1997, a capacitação permanente dos docentes do curso não era sistematizada, inexistindo uma comissão constituída com essa finalidade. Com a tomada de decisão da implantação do currículo integrado a partir de 1998, foi criada uma grande demanda de recursos humanos destinados a suprir todas as funções a serem desempenhadas no novo modelo curricular.

Em resposta a essa demanda, constituiu-se em 1997 a Comissão de Treinamento, que ofereceu, de forma oficial, nos primeiros anos do novo currículo, um extenso e diverso leque de ações didático-pedagógicas.

As atividades da CT eram oferecidas com bastante freqüência, mas enfrentavam grande resistência de participação dos docentes, que não julgavam importante essa tarefa em sua vida acadêmica. De forma velada ou não, tinham dificuldades em aceitar as mudanças curriculares. Muitos cursos de treinamento, em seus diversos formatos, tiveram poucos inscritos ou até foram cancelados por falta de inscrições.

Nas inovações curriculares, entre as muitas qualidades necessárias ao suporte exigido na área de capacitação, constam recursos humanos treinados, criatividade e ousadia. É preciso criar estratégias para mudar a situação de "inércia" em que muitos professores se colocam frente às novas tarefas. Muitos têm profundos conflitos de valores, poder e autoridade, mas a maioria dos docentes oponentes pode ser convencida a discutir suas diferenças com a nova metodologia, desde que não seja desvalorizada sua atuação pregressa no curso médico ${ }^{17}$. É importante que sejam expostos às novas idéias num contexto conhecido para eles e no qual se sintam seguros.

Neste sentido, devem ser compreendidos os processos de capacitação não sistematizada ou informal. Eles tornam viável o contato mais estreito entre professores, realizando uma tarefa proposta com um objetivo conhecido. Durante o trabalho, os docentes não inseridos permitem uma aproximação e podem tomar conhecimento de informações sobre a nova proposta curricular. Possibilitam a discussão desarmada dos diferentes pontos de vista e a compreensão de tópicos antes não esclarecidos suficientemente. Constatam que podem existir opiniões comuns sobre vários aspectos. Por fim, podem se sentir motivados ao desempenho de alguma função no novo currículo ${ }^{17}$.

A prática educacional deve buscar contextos diversificados de cenários. A literatura pertinente descreve experiência de busca da construção da professoralidade por meio da prática reflexiva em um setor de Clínica Médica. Os sujeitos são médicos-professores, alunos e pacientes. As observações do espaço das práticas, o discurso dos participantes, os procedimentos clínicos e os encontros e conversas interativas constituíram elementos importantes no sentido de atingir o objetivo proposto ${ }^{18}$. As experiências descritas neste estudo, denominadas atividades de capacitação não sistemáticas, utilizaram contextos e cenários diversos, valorizando o diálogo com os docentes. 
A primeira experiência analisada - "reunião de tutores" - foi considerada formação complementar ao desempenho do tutor, função nuclear na metodologia da ABP. O curso preparatório oficial ofertado não constituía um treinamento completo aos docentes por ter duração muito limitada. Cursos avançados ou de aprofundamento na formação de tutores não são incomuns em outras escolas ${ }^{7}$. Na UEL, tiveram baixa adesão por envolverem maior disponibilidade de tempo docente para essa tarefa.

O espaço na reunião de tutores pode ser utilizado para a capacitação formal complementar dos tutores ou mesmo para a capacitação em outras funções. Um curso seqüencial com curtas intervenções didático-pedagógicas semanais pode ser planejado para ocorrer durante o desenvolvimento de um módulo temático. Experiências com este formato ocorreram em resposta à demanda surgida após a pesquisação com os coordenadores dos módulos. Alguns coordenadores identificaram tutores inseguros durante seu desempenho nas sessões tutoriais. ACCD planejou um treinamento especial durante as reuniões de tutores, nas quais dificuldades específicas dos grupos de docentes foram discutidas e sugeridas formas de enfrentamento. Os resultados foram animadores.

Outras três experiências relatadas - a pesquisação sobre inserção e desenvolvimento docente, a revisão de conteúdos dos módulos temáticos e o inquérito com os preceptores do internato - permitiram diferentes graus de capacitação individual de professores, e, mais que isso, possibilitaram a aproximação dos docentes ao currículo integrado e o diálogo com os resistentes.

O interesse em buscar a visão dos professores acerca da implantação das inovações curriculares e a verificação do grau de participação de cada um nas atividades do novo processo representaram uma valorização da opinião e do trabalho individual e um incentivo ao diálogo.

A teoria da ABP propõe que os alunos sejam aprendizes autodirigidos e que sejam capazes de abranger de forma suficiente a matéria de estudo ${ }^{12}$. Num processo de inovação curricular, ainda em fase de implementação, os professores mostram incertezas e preocupações, e não se sentem seguros quanto a isso.

Os trabalhos da CAC deram visibilidade aos conteúdos das antigas disciplinas no currículo nuclear. Professores das "áreas básicas e clínicas" tiveram espaço para expressar suas preocupações e propor sugestões, colaborando na construção do novo currículo, entendendo melhor seu caráter de integração disciplinar. Embora focado em conteúdos, o trabalho divulgou informações sobre as inovações a um grande número de docentes. Essa atitude colaborou para diminuir a resistência dos professores e evitou atitudes de franco enfrentamento ou boicote de atividades.
Em outra experiência relatada - o inquérito com os coordenadores de módulos temáticos - havia necessidade de um diagnóstico mais preciso dos problemas encontrados durante o desenvolvimento modular. Era importante localizar e quantificar as disfunções. O inquérito forneceu subsídios importantes à CCD para o planejamento de ações saneadoras a médio e longo prazos. Constituiu um passo significativo para homogeneizar as atividades necessárias à efetiva condução dos módulos. A própria aplicação do questionário permitiu um diálogo personalizado e interativo com os coordenadores, redirecionando possíveis desvios no gerenciamento do módulo e constituindo importante atividade de capacitação.

A institucionalização de mudanças educacionais significativas é um processo evolutivo lento, que exige das lideranças grande dose de paciência e muito esforço.

Um estudo sobre formação de professores e práticas educativas de professores de Medicina identificou, entre outros dados, os limites presentes na prática pedagógica e os dilemas do cotidiano docente, apontando a necessidade de um programa de formação e desenvolvimento docente permanente ${ }^{19}$.

No aspecto particular da capacitação dos professores, é importante ajudá-los a perceber seu papel em cada fase do processo das mudanças e dar atenção às suas dúvidas, necessidades e opiniões ${ }^{18}$. Em nossa experiência, no decorrer do processo de implantação das mudanças, as novas demandas surgidas com a prática diária não foram analisadas sempre com a devida atenção e sensibilidade. Nem sempre houve capacidade de respostas criativas e efetivas, mas as atividades aqui analisadas constituíram as respostas possíveis a demandas locais identificadas. Os professores envolvidos e os dirigentes do curso aprenderam e continuam a aprender sobre o assunto. Mesmo a curta história das denominações da Comissão especial existente - de Comissão de Treinamento para Comissão de Capacitação e para Comissão de Educação Permanente - é ilustrativa do esforço autocrítico que mobiliza o curso de Medicina da UEL nos últimos anos.

Ministério da Educação. Conselho Nacional de Educação. Câmara de Educação Superior. Diretrizes curriculares nacionais do curso de graduação em medicina. Brasília, 2001

\section{REFERÊNCIAS}

1. Ministério de Educação. Comissão Interinstitucional de Avaliação do Ensino Médico. Relatório final da II fase do projeto interinstitucional da avaliação do ensino médico. Rio de Janeiro; 1999. 
2. Ministério da Educação. Conselho Nacional de Educação. Câmara de Educação Superior. Diretrizes curriculares nacionais do curso de graduação em medicina. Brasília; 2001

3. Ministério da Saúde. Ministério da Educação. Organização Panamericana da Saúde. PROMED - Programa de Incentivo a Mudanças Curriculares nos Cursos de Medicina. Brasilia: Secretaria de Políticas de Saúde; 2002.

4. Ministério da Saúde. Ministério da Educação. Programa nacional de reorientação da formação professional em saúde PRÓ-SAÚDE. Brasilia; 2005. 80p.

5. Gordan PA. Currículos inovadores: o desafio da inserção docente. In: Batista NA, Batista SH org. Docência em saúde: temas e experiências. São Paulo: Senac; 2004. p. 187-200.

6. Costa NMSC. Docência no ensino médico: por que é tão difícil mudar? Rev Bras Educ Med 2007; 31(1):21-30.

7. Venturelli J, Fiorini VML. Programas educacionais inovadores em escolas médicas: capacitação docente. Rev Bras Educ Med 2001;25(5):7-21.

8. Des Marchais JE. A student-centred, problem-based curriculum: 5 years' experience. CMAJ 1993; 148(9): 1567-72.

9. Lima GZ, Almeida HGG, Ferreira Filho OF, Linhares REC, Colus IMS, Oberdierk HI. Aprendizagem Baseada em problemas(ABP): construindo a capacitação em Londrina. Rev Bras Educ Med 2003;27(1):5-11.

10. Ferreira Filho OF, Almeida HGG, Colus IMS, Oberdierk HI, Linhares REC, Gordan PA et al. Visão docente do processo de implementação da Aprendizagem Baseada em Problemas (ABP) no curso médico da Universidade Estadual de Londrina (UEL). Rev Bras Educ Med 2002;26(3):175-83.

11. Almeida HGG, Ferreira Filho OF, Colus IMS, Linhares REC, Takahashi OS, Aguiar AC. Elaborando a capacitação de tutores: subsídios da prática. Rev Bras Educ Med 2003;27(3): 191-9.

12. Moust JHC, Van Berkel HJM, Schmith HG. Signs of erosion: reflections on three decades of problem-based learning at Maastricht University. Higher Education 2005;50(4):665-83.

13. Universidade Estadual de Londrina. Centro de Ciências da Saúde. Colegiado do Curso de Medicina. Relatório das atividades da Comissão de Revisão Curricular. Londrina; 2002.

14. Ferreira Filho OF, Colus IMS, Almeida HGG, Oberdierk HI, Linhares RE. Experiências de capacitação docente em um currículo integrado. [pôster apresentado 41. Congresso Brasileiro de Educação Médica; 2003 nov. 7-10; Florianópolis]

15. Universidade Estadual de Londrina. Centro de Ciências da Saúde. Colegiado do Curso de Medicina. Comissão de Acompanhamento Curricular. Relatório do inquérito realizado com os preceptores do Internato Médico sobre a programação dos estágios da quinta e sexta séries do curso de Medicina da Universidade Estadual de Londrina; 2004.

16 Universidade Estadual de Londrina. Centro de Ciências da Saúde. Colegiado do Curso de Medicina. Projeto Político-Pedagógico do Curso de Medicina; 2004: 5-6.

17. Cox K. Persuading colleagues to change: fifteen lessons learned from more than 20 years of trying. Education for Health 1999;12(3):347-53.

18. Silva JG. Educação Médica: Construindo a Professoralidade. Rev. Bras Educ Méd 2005; 29(3):222. [resumo Tese de Doutorado em Educação - Pontifícia Universidade Católica. Defendida em: 5 dez. 2003].

19. Costa NMSC. A formação e as práticas educativas de professores de medicina: uma abordagem etnográfica. Rev Bras Educ Med 2005; 29(2): 152. [resumo Tese de Doutorado em Educação - Pontifícia Universidade Católica. Defendida em: 8 abr. 2005].

\section{CONFLITOS DE INTERESSE}

Declarou não haver

\section{ENDEREÇO PARA CORRESPONDÊNCIA}

Henriqueta Galvanin Guidio de Almeida Av. Rio de Janeiro, 1630 - apto 902 - Jardim Ipiranga 86010-150 - Londrina - PR guidio@sercomtel.com.br 